\title{
Effects of Asparagus racemosus Root Extracts on Serum Lipid Profiles, Lipid Peroxidation and Superoxide Dismutase in Ovariectomized Rat
}

\author{
Ladachart Taepongsorat ${ }^{1 *}$, Methin Phadungkit ${ }^{2}$
}

\section{Ladachart Taepongsorat ${ }^{1, *}$ Methin Phadungkit ${ }^{2}$}

'Faculty of Medicine, Mahasarakham University, Mahasarakham 44000, THAILAND.

2Pharmaceutical Chemistry and Natural Products Research Unit, Faculty of Pharmacy, Mahasarakham University, Mahasarakham 44150, THAILAND.

Correspondence:

\section{Ladachart Taepongsorat}

Faculty of Medicine, Mahasarakham University, Mahasarakham 44000, THAILAND.

Phone no: +66 43754121

Email:ladachart20@yahoo.com

History

- Submission Date: 17-04-2018;

- Review completed: 03-05-2018;

- Accepted Date: 11-07-2018.

DOI : 10.5530/pj.2018.5.175

Article Available online

http://www.phcogj.com/v10/i5

\section{Copyright}

(c) 2018 Phcog.Net. This is an open-access article distributed under the terms of the Creative Commons Attribution 4.0 International license.

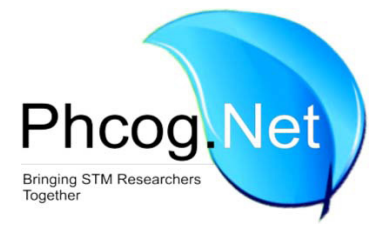

\begin{abstract}
Background: Once rats have been ovariectomized they have a high risk of cardiovascular disease due to changes in the blood cholesterol and lipid profile. Objective: To investigate the effects of Asparagus racemosus (AR) root extract on the serum lipid profiles, lipid peroxidation and antioxidant levels in ovariectomized rats. Methods: Twenty-five, two month-old female Wistar rats were randomly divided into five groups: SH, OVX,OEE, OAAR and OEAR. The daily doses of $500 \mathrm{mg} / \mathrm{KgBW}$ of the AR root extracts for five weeks. The levels of serum TG, TC, HDL, LDL, the liver, kidney and uterine tissue lipid peroxidation and SOD levels were determined. Results: Serum TC and LDL showed no significant differences in any groups. Serum TG of the OAAR and OEAR groups were not significantly different. The serum HDL of the OAAR and OEAR groups were significantly lower than the OEE group. The liver MDA levels of the OAAR and OEAR groups were significantly decreased compared with the OVX and OEE groups while the SOD level of the OAAR group was significantly increased. The MDA levels in the kidney and uterine of the treated group showed no significant difference. The SOD levels in the kidney of the treated group were not different but the SOD levels in uterine were significantly decreased. Conclusion: It can be believed that the lipid profiles were maybe regulated via estrogen. The $A R$ extract has low effects on the lipid profiles at this dose and duration of treatment. The capacity of the extracts to decrease the MDA level and increase the SOD level in this study clearly reflected the antioxidant efficiency of these substances.
\end{abstract}

Key words: Asparagus racemosus, Lipid profiles, Malondialdehyde, Superoxide dismutase, Ovariectomized rat

\section{INTRODUCTION}

Previous work has indicated that there is an increased risk of coronary heart disease under the menopause as a result of differences in the clotting and fibrinolytic factors, lipid profile and vessel function. ${ }^{1}$ For over 30 years blood metabolism has been improved by estrogen replacement, while for 20 years there has been increased use of a combined estrogen-progesterone treatment. ${ }^{2}$ There are also concerns associated with synthetic estrogen such as cancer (endometrial and breast), interference with a natural process and vaginal bleeding. ${ }^{3}$ Phytoestrogens are assumed to produce minimal side effects and studies have shown that phytoestrogens are effective in the prevention and amelioration of the metabolism of sex hormones and blood lipids in women who are postmenopausal. ${ }^{4}$

Asparagus racemosus (AR), also called shatavari, is a member of the familly Liliaceae, an Indian climbing plant. While in Thailand, AR is known as rak-sam-sib or sam-roi-rak. The extracts of the roots of AR have in the last few years been determined to have a phytoestrogenic effect and help with neurodegenerative disorders, in addition to effects on antidiarrheal, antidyspepsia, adaptogenic, cardioprotective, antibacterial, immunoadjuvant and antitussive. ${ }^{5}$ There are two major forms in which the root extracts of AR have been used (methanolic and aqueous extracts) as tablets, powders in tablets or a syrup form. ${ }^{6}$ In addition, there have been reports of activities related to immunostimulant, antihepatotoxic or antioxytocic. ${ }^{5}$ In laboratory animals, there have been recent reports the extracts of $\mathrm{AR}$ roots have antioxidant and antidiarrheal effects. ${ }^{7-8}$

In rats, the lipid peroxidation (malondialdehyde: MDA) decreased while there were increases in superoxide dismutase (SOD), catalase and ascorbic acid by the methanolic root extracts. ${ }^{9-10}$ In addition,
Cite this article: Ladachart Taepongsorat, Methin Phadungkit. Effects of Asparagus racemosus Root Extracts on Serum Lipid Profiles, Lipid Peroxidation and Superoxide Dismutase in Ovariectomized Rat. Pharmacogn J. 2018;10(5):1036-41 
AR has recently been shown to contain 10 steroidal saponins ${ }^{11}$ and racemofuran. ${ }^{12}$ Rat liver mitochondria were protected by aqueous extracts due to the prevention of radiation-induced loss of protein thiols while SOD was inactivated ${ }^{13}$ along with oxidative stress and hepatotoxicity amelioration. ${ }^{14}$

The objective of this research was to investigate the effects of Asparagus racemosus root extract (AR) on serum lipid profiles, liver function, renal function, lipid peroxidation and superoxide dismutase (SOD) in ovariectomized rats.

\section{MATERIALS AND METHODS}

\section{Plant Material}

The plant roots of AR were collected from Khonkaen province, Thailand and identified by the authors. The voucher specimens were deposited at the Pharmaceutical Chemistry and Natural Product Research Unit, Faculty of Pharmacy, Mahasarakham University, Thailand (MSU. PH-LIL-AR1). The roots were washed thoroughly with tap water and dried at $37^{\circ} \mathrm{C}$ in an incubator, and then cut into small pieces that were powdered finely before being using for the extractions. The extractions were performed using soxhlet apparatus and concentrated to dryness under a reduce pressure and a controlled temperature using evaporator and a freeze-dryer, respectively. For the experiments, $500 \mathrm{mg} / \mathrm{kgBW}$ of the dried extracts were used.

\section{Experimental Animals and Design}

Female Wistar rats at seven weeks old, weighing approximately 150-180g from the National Laboratory Animal Center, Mahidol University, Salaya Campus, Thailand were used for the experiment. Four rats were housed in one well ventilated standard rat cage under standard conditions $(26 \pm 2$ ${ }^{\circ} \mathrm{C}, 12 \mathrm{~h}$ light-dark cycle) with ad libitum access to drinking water and fed standard rat chow (CP mia feed No.082). The care and procedures adopted for the present investigation were in accordance with the approval of the Institutional Animal Care and Use Committee, Mahasarakham University (IACUC-MSU), Thailand (Approval number 0011/2016).

After a seven day adaptation period, the rats were operated on and randomized into five groups, with five rats in each group, as follows: Group 1; sham group ( $\mathrm{SH})$ : the same surgical procedure was performed in the sham-operate rats except that the ovaries were not removed. The sham rats received the vehicle without any substance. Groups 2-5; the surgical procedure was performed and the ovaries were removed. Group 2: control group (OVX); OVX rats received the vehicle without any substance. Groups 3-4: treatment groups; OVX rats received $500 \mathrm{mg} / \mathrm{kgBW}$ of aqueous extract (OAAR) or ethanolic extract of the AR roots (OEAR), respectively. Group 5: OVX rats received 17 a-ethynylestradiol $0.1 \mathrm{mg} /$ $\mathrm{kgBW}$ for a positive control (OEE). Each rat received their substances by feeding needle, daily for five weeks. All treatments were initiated pre- cisely 10 days after surgery. Their body weights were recorded every day during the experimental period. At the end of the experiment, the rats were sacrificed under anesthesia and blood was collected immediately by cardiac puncture; serums were separated by centrifugation. The liver, kidney and uterus were excised, weighed and kept at $-80^{\circ} \mathrm{C}$ until analyzed.

\section{Biochemical parameters analysis}

Biochemical parameters, such as blood glucose (BG), liver function test: serum aspartate aminotransferase (AST), serum glutamate pyruvate transaminase (ALT), renal function test: blood urea nitrogen (BUN), creatinine (Cr) and lipid profiles: triglyceride (TG), total cholesterol (TC), low density lipoprotein (LDL) and high density lipoprotein (HDL) were measured in a Clinical Autometric Chemistry Analyzer (Tecom $6060 \mathrm{~L}$ ) at the M-LAB, Mahasarakham laboratory, Thailand using standard laboratory techniques.

\section{Lipid peroxidation and SOD antioxidant enzyme activity}

The liver, kidney and uterus tissues were homogenized in a potassium chloride buffer with a tissue homogenizer and lipid peroxidation was estimated according to the method of Ohkawa..$^{15}$ Concentrations were determined from a standard curve using Tetramethoxpropane (TMP) and expressed as nmol of malondialdehyde (MDA) formed per $100 \mathrm{mg}$ protein of tissue. The method of Lowry et al. ${ }^{16}$ was used to examine the protein content.

Superoxide dismutase (SOD) activities in liver, kidney and uterus homogenates were determined using the nitrobluetetrazolium reduction method with Sigma-Aldrich determination kit (product number 19160).

\section{Statistical analysis}

All data were presented as a mean \pm SEM.A one-way ANOVA followed by a Student's t-test were used to determine the statistical significance. P-values $<0.05$ were considered as statistically significant.

\section{RESULTS}

\section{Vaginal cellular differentiation}

Daily vaginal smear cytology was used to identify the estrous cycle phases of the rats, as regular cycles are required. The vaginal smear was examined from all rats every morning for 35 days (five weeks). Sham rats had a normal estrous cycle. Until the experiment was completed, the ovariectomized rats showed the diestrous phase (leukocyte cells). In the positive control rats, vaginal cells showed maturation in response to 17 -ethynylestradiol at a dose of $0.1 \mathrm{mg} / \mathrm{kgBW}$ on the third day during the 35 day exposure period. Both the aqueous and ethanolic extracts of the AR roots induced significant cornification cells when compared to the OVX group on the fifth day of the exposure period.

Table 1: Body weight, uterine weight, relative uterine weight, liver weight, relative liver weight, kidney weight and relative kidney weight (mean \pm SEM).

\begin{tabular}{|c|c|c|c|c|c|c|c|}
\hline Group & Body weight (g) & Uterine weight (g) & $\begin{array}{l}\text { Relative uterine } \\
\text { weight }(x 100)\end{array}$ & Liver weight (g) & $\begin{array}{l}\text { Relative liver } \\
\text { weight (x100) }\end{array}$ & Kidney weight (g) & $\begin{array}{c}\text { Relative kidney } \\
\text { weight }(x 100)\end{array}$ \\
\hline $\mathrm{SH}$ & $266 \pm 11$ & $0.35 \pm 0.02$ & $0.13 \pm 0.00$ & $7.23 \pm 0.29$ & $2.73 \pm 0.14$ & $1.50 \pm 0.09$ & $0.56 \pm 0.02$ \\
\hline OvX & $288 \pm 9^{*}$ & $0.17 \pm 0.01^{*}$ & $0.06 \pm 0.00^{*}$ & $7.50 \pm 0.35$ & $2.60 \pm 0.07$ & $1.56 \pm 0.02$ & $0.54 \pm 0.01$ \\
\hline OAAR & $273 \pm 6^{p}$ & $0.25 \pm 0.03^{* * \mathrm{p}}$ & $0.09 \pm 0.00^{* * \mathrm{p}}$ & $6.41 \pm 0.09^{* * \mathrm{p}}$ & $2.36 \pm 0.05^{* * \mathrm{p}}$ & $1.36 \pm 0.03^{\#}$ & $0.50 \pm 0.00^{* * \mathrm{p}}$ \\
\hline OEAR & $276 \pm 8^{p}$ & $0.24 \pm 0.02^{* \mathrm{p}}$ & $0.09 \pm 0.01^{* * \mathrm{p}}$ & $6.86 \pm 0.24$ & $2.50 \pm 0.14^{\mathrm{p}}$ & $1.47 \pm 0.09$ & $0.53 \pm 0.03$ \\
\hline OEE & $224 \pm 6^{* *}$ & $0.43 \pm 0.04^{\#}$ & $0.19 \pm 0.01^{* *}$ & $7.69 \pm 0.43$ & $3.42 \pm 0.11^{* \#}$ & $1.34 \pm 0.07^{\#}$ & $0.59 \pm 0.02$ \\
\hline
\end{tabular}

", ", p show significant differences $(\mathrm{p}<0.05)$ compared with SH, OVX and OEE groups, respectively. 
Table 2: Serum biochemical levels (mean \pm SEM).

\begin{tabular}{cccccc}
\hline Group & $\begin{array}{c}\text { AST } \\
(\mathrm{U} / \mathrm{L})\end{array}$ & $\begin{array}{c}\text { ALT } \\
(\mathrm{U} / \mathrm{L})\end{array}$ & $\begin{array}{c}\text { BUN } \\
(\mathrm{mg} / \mathrm{dl})\end{array}$ & $\begin{array}{c}\mathrm{Cr} \\
(\mathrm{mg} / \mathrm{dl})\end{array}$ & $\begin{array}{c}\text { BG } \\
(\mathrm{mg} / \mathrm{dl})\end{array}$ \\
\hline SH & $153.75 \pm 20.5$ & $41.5 \pm 8.21$ & $20 \pm 1.75$ & $0.53 \pm 0.04$ & $103 \pm 11.28$ \\
OVX & $147.40 \pm 11.41$ & $34.8 \pm 3.25$ & $22 \pm 0.59$ & $0.48 \pm 0.04$ & $107 \pm 4.58$ \\
OAAR & $148.60 \pm 15.51$ & $33.6 \pm 5.35$ & $20 \pm 0.39$ & $0.55 \pm 0.07$ & $111 \pm 2.01$ \\
OEAR & $116.80 \pm 14.94$ & $30.2 \pm 5.16$ & $19 \pm 1.59$ & $0.47 \pm 0.04$ & $109 \pm 3.79$ \\
OEE & $123.80 \pm 10.55$ & $37.0 \pm 3.69$ & $23 \pm 2.68$ & $0.45 \pm 0.03$ & $111 \pm 7.44$ \\
\hline
\end{tabular}

Table 3: Lipid profile levels in serum (mean \pm SEM).

\begin{tabular}{ccccc}
\hline Group & $\begin{array}{c}\text { Cholesterol } \\
(\mathrm{mg} / \mathrm{dl})\end{array}$ & $\begin{array}{c}\text { Triglyceride } \\
(\mathrm{mg} / \mathrm{dl})\end{array}$ & $\begin{array}{c}\mathrm{HDL} \\
(\mathrm{mg} / \mathrm{dl})\end{array}$ & $\begin{array}{c}\mathrm{LDL} \\
(\mathrm{mg} / \mathrm{dl})\end{array}$ \\
\hline SH & $53.75 \pm 8.38$ & $119 \pm 3.74$ & $35.2 \pm 3.04$ & $54.73 \pm 7.21$ \\
OVX & $67.4 \pm 6.46$ & $110.8 \pm 6.87$ & $36.18 \pm 2.29$ & $67.70 \pm 6.12$ \\
OAAR & $65.0 \pm 5.52$ & $111.6 \pm 3.5$ & $36.74 \pm 1.94^{\mathrm{p}}$ & $61.42 \pm 4.63$ \\
OEAR & $71.2 \pm 7.13$ & $106.8 \pm 3.06^{*}$ & $39.96 \pm 3.76^{* \mathrm{p}}$ & $64.92 \pm 5.12$ \\
OEE & $69.0 \pm 6.36$ & $114.8 \pm 6.63$ & $51.98 \pm 3.66^{* *}$ & $53.82 \pm 7.43$ \\
\hline
\end{tabular}

", ", p show significant differences $(\mathrm{p}<0.05)$ compared with $\mathrm{SH}$, OVX and OEE groups, respectively.

\section{Body Weight and Organs Weight}

The body and organs weight are in Table 1. The OVX group had rapid weight gain in the week following ovariectomy, which remained higher than every other group for five weeks. At the end of the experiments, the OVX group tended to increase in final body weight when compared to the $\mathrm{SH}$ and both treated groups. Body weight in the OEE group began to significantly decrease in the first week after the start of the treatment when compared with OVX group. The SH and treatment groups showed a gain in body weight but this alteration was less than that in the OVX rats. The treatment with aqueous and ethanolic extracts significantly increased in the body weight when compared to the positive control group.

The changes in the uterine weight and relative uterine weight are shown in Table 1. The OVX group had the significantly lowest uterine weight and relative uterine weight. The uterine weight in the OEE group was significantly increased when compared with the OVX group, whereas the relative uterine weight in the OEE group was also significantly increased when compared with the OVX and SH groups. Whereas uterine weight and relative uterine weight in the OAAR, OEAR groups were significantly decreased when compared with the SH and OEE groups. The uterine weight and relative uterine weight of the treated groups were significantly increased in comparison with the OVX group.
The liver weight and relative liver weight of the OVX group were not significantly different when compared with the SH, OEE and OEAR groups. In the OAAR group, liver weight and relative liver weight were significantly lower than in the $\mathrm{SH}$, OVX and OEE groups. The relative liver weight of the OEE group was increased significantly when compared with the SH and OVX groups. The relative liver weight of the OAAR group was significantly lower than the OEE group. The relative liver weight of the OEAR was decreased significantly when compared with the OEE group.

The kidney weight and relative kidney weight of the OVX group had no significant differences when compared with the SH, OEE and OEAR groups. The kidney weight of the OEE and OAAR groups decreased significantly when compared with the OVX group. The relative kidney weight of the OAAR group decreased when compared with the SH, OVX and OEE groups.

\section{Effects of extracts on serum AST, ALT, BG, BUN, Cr}

The results of the blood biochemical tests in rats are shown in Table 2. The serum AST, ALT, BUN, Cr and BG did not change with the treatment.

These results showed that the extract at a daily dose of $500 \mathrm{mg} / \mathrm{kgBW}$ in ovariectomized rats for five weeks had no effects on liver or kidney function and serum blood glucose.

\section{Effects of extracts on serum lipid profiles}

The effects of the AR root extracts on the serum lipid profiles are summarized in Table 3. Compared with the SH group, serum TC and LDL tended to increase in all groups. However, serum TC and LDL showed no significant differences in any groups.

In the OEAR group, the serum TG level was significantly lower than in the $\mathrm{SH}$ group. The serum TG of the OAAR and OEAR groups were not significantly different when compared with the OVX group.

The serum HDL level in the OEE group was significantly higher than in the SH and OVX groups. The serum HDL of the OAAR and OEAR groups was significantly lower than the OEE group.

\section{Effects of extracts on MDA and SOD}

The levels of MDA and SOD in the tissues are shown in Table 4. In liver, the MDA level was significantly increased, whereas the SOD level wassignificantly decreased in the OVX and OEE groups when compared with the SH group. The MDA levels in the liver of the OAAR and OEAR groups were significantly decreased when compared with the OVX and OEE groups. The SOD level in the liver of the OAAR group was significantly increased when compared with the OVX and OEE groups. The SOD level in the liver of the OEAR group was significantly decreased when compared with the SH group.

Table 4: The MDA (nmol/100 mg protein) and SOD (unit/100 mg protein) levels.

\begin{tabular}{|c|c|c|c|c|c|c|}
\hline \multirow[t]{2}{*}{ Group } & \multicolumn{2}{|c|}{ Liver } & \multicolumn{2}{|c|}{ Kidney } & \multicolumn{2}{|c|}{ Uterine } \\
\hline & MDA & SOD & MDA & SOD & MDA & SOD \\
\hline $\mathrm{SH}$ & $2.64 \pm 0.16$ & $0.5 \pm 0.04$ & $6.54 \pm 0.23$ & $0.48 \pm 0.03$ & $181.5 \pm 46.4$ & $7.64 \pm 0.76$ \\
\hline OVX & $4.44 \pm 0.56^{\star}$ & $0.34 \pm 0.02^{*}$ & $4.49 \pm 0.79$ & $0.49 \pm 0.05$ & $219.11 \pm 83.2$ & $12.24 \pm 0.74$ \\
\hline OAAR & $2.05 \pm 0.29^{\# p}$ & $0.41 \pm 0.02^{\# p}$ & $5.01 \pm 0.44^{*}$ & $0.53 \pm 0.05$ & $217 \pm 22.3$ & $8.14 \pm 2.92^{\# p}$ \\
\hline OEAR & $1.49 \pm 0.12^{* \# \mathrm{p}}$ & $0.36 \pm 0.03^{*}$ & $5.60 \pm 0.33$ & $0.47 \pm 0.02^{\mathrm{p}}$ & $498.93 \pm 116.1^{\mathrm{pa}}$ & $10.22 \pm 1.27^{p}$ \\
\hline OEE & $4.16 \pm 0.15^{\star}$ & $0.33 \pm 0.01^{*}$ & $4.14 \pm 0.58^{*}$ & $0.64 \pm 0.05^{*}$ & $171.18 \pm 23.7$ & $3.27 \pm 0.43^{\star \#}$ \\
\hline
\end{tabular}

*, \#, p, ashow significant differences $(\mathrm{p}<0.05)$ compared with $\mathrm{SH}, \mathrm{OVX}, \mathrm{OEE}$ and OAAR groups, respectively. 
The MDA and SOD levels in the kidney of the OVX group showed no significant differences. The MDA levels in the kidney tissue of the OEE group were significantly decreased when compared with the $\mathrm{SH}$ group, while the SOD level was significantly increased when compared with the $\mathrm{SH}$ group. The MDA levels in the kidney tissue of the OAAR group were significantly decreased when compared with the SH group, whereas the SOD showed no significant difference. The SOD level in the kidney tissue was significantly decreased in the OEAR when compared with the OEE group.

The MDA levels in the uterine of the OVX, OAAR and OEE groups showed no significant differences. In the OEAR group, the MDA and SOD levels in the uterine tissue were significantly increased when compared with the OEE group. The SOD level in the uterine tissue were significantly increased in the OVXgroup and tended to increase in the OAAR and OEAR groups. The SOD level in the uterine tissue was significantly decreased in the OEE group.

\section{DISCUSSION}

Cornification of the epithelial cells was induced via synthetic estrogens and phytoestrogens and their estrogenic activity. ${ }^{17}$ After ovariectomy, all the rats had leucocyte populations affirming the complete removal of the ovaries. ${ }^{18}$ Vaginal smears of OVX rats did not show any cornification proving the absence of endogenous estrogens. ${ }^{17-18}$ In this study, cornification cells in positive control, OEE group responded to $17 \alpha$-ethynylestradiol at a daily dose of $0.1 \mathrm{mg} / \mathrm{kgBW}$ on the third day, $17 \beta$-ethynylestradiol at a daily dose of $50 \mu \mathrm{g} / \mathrm{kgBW}^{19}$ and estradiol valerate at a dose of $1 \mathrm{mg} / \mathrm{kgBW}$ on the fifth day of the exposure period. ${ }^{20}$ Both aqueous and ethanolic extracts of the root of AR induced significant cornification of cells on the fifth day of the exposure period. In this study, the cornification of the vaginal smear in the OVX rats treated with the AR extract can be attributed to its estrogenic potential.

Estrogen was found to have an important regulatory effect on female adipose deposition ${ }^{21-23}$ and may also play an important regulatory role in adipocyte metabolism. ${ }^{24}$ Ovarian hormone withdrawal leads to significant increases in body weight and visceral fat, serum adiponectin and triglyceride. ${ }^{25}$ It is well documented that post ovariectomy, estrogen withdrawal leads to the accumulation of energy store (fat deposition) and subsequently an increase in the body weight of animals. ${ }^{26}$ The wellknown elevation of body weight involves a shift in energy metabolism due to ovarian hormone deficiency. ${ }^{26}$ Adiponectin is the most abundant protein derived from adipocytes, ${ }^{27}$ and changes in other biological markers in adipose tissue may be a physiological response to maintain sensitivity to insulin in women who have experienced the menopause. ${ }^{28}$ In this study, the body weight gains in SH, OVX, OAAR and OEAR rats were similar, but the body weight gain in OEE rats decreased. The dose and type of estrogen may affect weight gain due to a regulatory role in adipocyte metabolism. Treatment with $17 \alpha$-ethynylestradiol caused significant decrease in body weight. In OVX animals it was possible for there to be a substantial reduction in body weight via estrogen replacement therapy, due to improved insulin sensitivity, but without an increase in adiponectin production meaning that the beneficial metabolic effects of the weight loss were from a mechanical perspective. ${ }^{29}$

One of the challenges associated with the menopause is weight gain due to increased visceral fat, which was linked to as diabetes, hypertension and dyslipidemia. ${ }^{30}$ There is mild obesity in the ovariectomized animal model so it can help indicate how adiposity is altered by hypoestrogenism. ${ }^{31}$ In the present study, ovariectomized rats experienced a gain of body weight that was in agreement with previous studies, ${ }^{22,25}$ which is due to an increase of abdominal fat. The uterine weight decreased in the OVX group and increased in the OEE group. ${ }^{32}$ Atrophy of uteri in the OVX group demonstrated the decrease in estrogen secretion. Admin- istration of the AR extract increased uterine weight although not as potently as estrogen. These results imply that the AR extract contains a weak estrogenic effect in vivo as well as in vitro. Uteri undergo innumerable physiological and biochemical changes under the influence of ovarian hormones such as estrogen and progesterone. ${ }^{33}$ Administration of estrogenic substances to ovariectomized rats often leads to proliferative changes in the uterine endometrium. ${ }^{34}$ As the OVX rats had lost their ovaries there was a significant reduction in uterine weight when comparingto the $\mathrm{SH}$ rats. The uterine weight increased significantly when $17 \alpha$-ethynylestradiol was administered. Animals treated with the AR root extract showed a significant increase in their uterine weight compared with the OVX group. Similar results have been reported earlier wherein plant extracts of estrogenic nature increased uterine weight in ovariectomized rats. ${ }^{35-36}$ Inovariectomized rats the traditional way to indicate the estrogenic potency and efficacy has been via uterotrophic effects. $^{37}$

There were no significant changes in the lipid profiles of male rats administered with the AR root powder. ${ }^{38}$ In this study, female rats administered with the aqueous and ethanolic extracts of the AR roots also had no significant changes in their lipid and antioxidant profiles. Estrogen increased HDL and TG while decreasing LDL and fat deposition in OVX animal models. ${ }^{39}$ As for the lipid profile, many studies have reported that the lipid profile undergoes changes during menopause and ovariectomy. In women, the menopause is associated with increased concentrations of TC, TG, LDL and decreased concentrations of HDL. ${ }^{40}$ In the present study, TG and HDL levels were increased in ovariectomized rats treated with $17 \alpha$-ethynylestradiol, but there were no significant differences in TC and LDL levels. Camara et al. ${ }^{25}$ and Antunes et al. ${ }^{41}$ indicated that in ovariectomized rats there were no significant changes in the levels of TC and LDL as in our present study. There was a significant difference in the lipid profiles between the OEE and SH groups. From these results it is possible that the lipid profile is regulated due to estrogen. In addition, estrogen therapy is well known to reduce body weight and fat deposition and result in favorable changes in plasma lipid profiles. ${ }^{42-44}$

Estrogen has been reported as a beneficial factor in preventing cardiovascular diseases, like atherosclerosis, by keeping cholesterol levels low in premenopausal women. Menopausal women lose this protection because of a dramatic decrease in estrogen levels as a result of natural atrophy of the ovaries. ${ }^{45}$ Ovariectomized rats were observed with increased levels of cholesterol, HDL and triglycerides. ${ }^{20}$ Whereas ovariectomized rats treated with an estradiol vale rate showed decreases in the levels of these makers. ${ }^{20}$ In this study, there were not significant differences in cholesterol, triglyceride, HDL and LDL levels in the ovariectomized groups. Ovariectomized rats treated with $17 a$-ethynylestradiol were found to have increased triglyceride and HDL levels. Ovariectomized rats treated with AR root extracts were not significantly different in the lipid profile levels compared with the SH and OVX groups.

Ovariectomized rats had no significant differences in HDL, LDL and TG but had increased TC. The estrogen group had elevated levels of LDL and TC. ${ }^{46}$ There were increases in the HDL levels and decreases in the LDL levels that were greater than those expected just from the postmenopausal period and old age. ${ }^{47}$ In this study, AR did not differ in the lipid profiles.

Oxygen free radicals damage membranes and biological structures, but the damage can be prevented by SOD that removes superoxide radical. ${ }^{48}$ The toxic free radicals can be removed by scavenging enzymes, such as SOD and CAT, in vivo. Reduced activities of SOD in the liver have been observed in ovariectomized rats and this results in a number of deleterious effects due to the accumulation of super oxide radicals. ${ }^{49}$

Oxidative stress was found to be inhibited by the AR root extracts as assessed by a decrease in liver and kidney MDA levels. Ovariectomized 
rats exhibited elevated levels of MDA and enzymic antioxidants SOD in uterine. Elevations in the SOD activity may be a compensatory mechanism for chronic overproduction of free radicals and oxidative stress inuterine of ovariectomized rats..$^{50}$

The precipitation of cholesterol can be induced in vitro via steroid glycosides, such as digitonin and tomatine $\mathrm{e}^{51-52}$ but they also prevent in vivo absorption affecting bile acid, ${ }^{52}$ the size and structure of micelles can be affected by several triterpenoid saponins, ${ }^{53}$ which causes changes in the absorption of bile acid as well inhibiting the absorption of cholesterol. ${ }^{51,53}$ In addition, saponins can result in reduced plasma LDL levels via the turnover of LDL to hepatic tissue being increased, and this becomes bile acid. ${ }^{54}$ Saponins have been reported to prevent pancreatic lipase activity by lowering $\mathrm{TG},{ }^{55}$ and from this when the VLDL levels reduce there could be a direct link to TG levels decreasing, ${ }^{56}$ however, this current work does not suggest any significant alterations on the TG or VLDL levels in the studied groups, and the possible mechanism for this is still unknown.

This work found that there were no significant differences between any of the groups for the TC in the serum. Due to saponins interfering with the enterohepatic circulation of bile acids and precipitating cholesterol from micelles they can prevent the intestinal absorption of cholesterol that limits the plasma cholesterol levels.

\section{CONCLUSION}

The results presented here support the use of estrogen in regulation of lipid profiles. AR root extracts have low effects on lipid profiles under this dose and duration treatment used here. The capacity of the extracts to decrease the MDA level and increase the SOD levels in this study clearly reflect the antioxidant efficiency of the AR root extracts.

\section{ACKNOWLEDGEMENT}

The authors would like to acknowledge the Faculty of Medicine, Mahasarakham University, Thailand for providing a financial grant. We are also grateful to the Department of Biology, Faculty of Sciences, Mahasarakham University for providing facilities and also, Dr. Pongsathron Thouchpramuong and Miss Arkira Srikhun for their help: ovariectomy and the collection of blood and tissues of animals.

\section{CONFLICT OF INTEREST}

The authors declare no conflict of interest.

\section{ABBREVIATIONS}

ALT: Serum glutamate pyruvate transaminase; AR: Asparagus racemosus; AST: Serum aspartate aminotransferase; BG: Blood glucose; BUN: Blood urea nitrogen; Cr: Creatinine; HDL: High density lipoprotein; LDL: Low density lipoprotein; MDA: Malondialdehyde; SOD: Superoxide dismutase; TC: Total cholesterol; TG: Triglyceride; SH: Sham-operated rats group; OVX: Ovariectomized rats group; OAAR: Ovariectomized rats + aqueous extract group; OEAR: Ovariectomized rats + ethanolic extract group; OEE: Ovariectomized rats $+17 \alpha$-ethynylestradiol group.

\section{REFERENCES}

1. Colacurci N, Chiàntera A, Fornaro F, de Novellis V, Man-zella D, Arciello A, Chiàntera $\mathrm{V}$, et al. Effects of soy isoflavones on endothelial function in healthy postmenopausal women. Menopause. 2005;12(3):299-307.

2. Glazier MG, Bowman MA. A review of the evidence for the use of phytoestrogens as a replacement for traditional estrogen replacement therapy. Arch Intern Med. 2001:161(9):1161-72

3. Ravnikar VA. Compliance with hormone replacement therapy: are women receiving the full impact of hormone replacement therapy preventive health benefits?. Women Health. 1992;2(2):75-80.
4. Yan FF, Liu Y, Liu YF, Zhao YX. Herba Epimedii water extract elevates estrogen level and improves lipid metabolism in postmenopausal women. Phytother Res. 2008:22(9):1224-8.

5. Kongkaneramit L, Witoonsardsilp W, Peeungvicha P, Ingkaninan K, Waranuch N, Sarisuta N. Antioxidant activity and antiapoptotic effect of Asparagus racemosus root extracts in human lung epithelial H460 cells. Exp Ther Med.2011;2(1): 143-8.

6. Bopana N. Saxena S. Asparagus racemosus-Ethnopharmacological evaluation and conservation needs. J Ethnopharmacol. 2007;110(1):1-15.

7. Hayes PY, Jahidin AH, Lehmann R, Penman K, Kitching W, De Voss JJ. Structure revision of shatavarins I and IV, the major component from the roots of Asparagus racemosus. Terahedron Letter. 2006;47(39):6965-9.

8. Joshi JDS. Chemistry of Ayurvedic crude drugs: Part VIII: Shatavari Structure elucidation of bioactive shatavarin I and other glycosides. Indian J Chem Section B Organ Chem. 1988;27(1):12-6.

9. Bhatnagar M, Sisodia SS, Bhatnagar R. Antiulcer and antioxidant activity of Asparagus racemosus Willd and Withania somnifera Dunal in rats. Ann NY Acad Sci. 2005;1056:261-78.

10. Sairam K, Priyambada S, Aryya NC, Goel RK. Gastroduodenal ulcer protective activity of Asparagus racemosus: an experimental, biochemical and histological study. J Ethnopharmacol. 2003;86(1):1-10.

11. Hayes PY, Jahidin AH, Lehmann R, Penman K, Kitching W, De Voss JJ. Steroidal saponins from the roots of Asparagus racemosus. Phytochemistry. 2008;69(3):796-804

12. Wiboonpun N, Phuwapraisirisan P, Tip-pyang S. Identification of antioxidant compound from Asparagus racemosus. Phytother Res. 2004;18(9):771-3.

13. Kamat JP, Boloor KK, Devasagayam TPA, Venkatachalam SR. Antioxidant properties of Asparagus racemosus against damage induced by $\gamma$-radiation in rat liver mitochondria. J Ethnopharmacol. 2000;71(3):425-35

14. Agrawal A, Sharma M, Rai SK, Singh B, Tiwari M, Chandra R. The effect of the aqueous extract of the roots of Asparagus racemosus on hepatocarcinogenesis initiated by diethylnitrosamine. Phytother Res. 2008;22(9):1175-82.

15. Ohkawa H, Ohishi N, Yagi K. Assay for lipid peroxides in animal tissues by thiobarbituric acid reaction. Anal Biochem. 1979;95(2):351-8.

16. Lowry $\mathrm{OH}$, Rosebrough $\mathrm{NJ}$, Farr $\mathrm{AL}$, Randall $\mathrm{RJ}$. Protein measurement with the Folin-Phenol reagent. J Biol Chem. 1951;193:265-75.

17. Malaivijitnond S, Chansri K, Kijkuokul P, Urasopon N, Cherdshewasart W. Using vaginal cytology to assess the estrogenic activity of phytoestrogen-rich herb. J Ethnopharmacol. 2006;107(3):354-60

18. Jawaid T, Awasthi A, Kamal M. Estrogenic activity of a hydro-alcoholic extract of Bambusa arundinaceae leaves on female wistar rats. J Adv Pharm Technol Res.2015;6(1):19-24.

19. Cordial RR, Baxa-Daguplo BM, Fermanes PM, Garcia AS, Clavel RM, Herradura $\mathrm{MO}$, et al. Estrogenic activity of Puerariaphaseoloides Roxb. Benth evaluated in ovariectomized Rats. Philippine J Sci. 2006;135(1):39-48.

20. Shailajan S, Kumaria S, Pednekar S, Menon S, Choudhury H, Matani A. Estrogenic potential of Flemingia vestita Benth Tubers in ovariectomized rat model. Pharmacognosy J. 2016;8(1):44-9.

21. Okura T, Koda M, Ando F, Niino N, Ohta S, Shimokata H. Association of polymorphisms in the estrogen receptor gene with body fat distribution. Int J Obes.2003;27(9):1020-7.

22. Ainslie DA, Morris MJ, Wittert G, Turnbull H, Proietto J, Thorburn AW. Estrogen deficiency causes central leptin insensitivity and increased hypothalamic neuropeptide Y. Int J Obes. 2001;25(11):1680-8.

23. Wajchenberg BL. Subcutaneous and visceral adipose tissue: their relation to the metabolic syndrome. Endocr Rev. 2000;21(6):697-738.

24. Tchernof A, Desmeules A, Richard C, Laberge P, Daris M, Mailloux J, et al. Ovarian hormone status and abdominal visceral adipose tissue metabolism. J Clin Endocrinol Metab. 2004;89(7):3425-30.

25. Camara C, Zhou LY, Ma Y, Zhu L, Yu D, Zhao YW, et al. Effect of ovariectomy on serum adiponectin levels and visceral fat in rats. J Huazhong Univ SciTechnolog Med Sci. 2014;34(6):825-9.

26. Arjmandi BH, Alekel L, Hollis BW, Amin D, Stacewicz-Sapuntzakis M, Guo P, et al. Dietary soybean protein prevents bone loss in an ovariectomized rat model of osteoporosis. J Nutr. 1996;26(1):161-7.

27. Maeda K, Okubo K, Shimomura I, Funahashi T, Matsuzawa Y, Matsubara K. cDNA cloning and expression of a novel adipose specific collagen-like factor apM1 (Adipose Most abundant Gene transcript 1). Biochem Biophys Res Commun. 1996;221(2):286-9.

28. Misso ML, Jang C, Adams J, Tran J, Murata Y, Bell R, et al. Differential expression of factors involved in fat metabolism with age and the menopause transition. Maturitas. 2005;51(3):299-306

29. Babaei P, Mehdizadeh R, Ansar MM, Damirchi A. Effects of ovariectomy and estrogen replacement therapy on visceral adipose tissue and serum adiponectin levels in rats. Menopause Int. 2010;16(3):100-4.

30. Milewicz A. Menopausal obesity and metabolic syndrome Pol Senior study Minerva Endocrinologica. 2012;37(1):93-101.

31. Wade GN, Gray JM, Bartness TJ. Gonadal influences on adiposity. Int J Obes 
1985;9(1):83-92.

32. Park Y, Kwon HY, Shimi MK, Rhyu MR, Lee Y. Improved lipid profile in ovariectomized rats by red ginseng extract. Pharmazie. 2011;66(6):450-3.

33. Mitra SK, Gopumadhavan S, Venkataranganna MV, Sharma DNK, Anturlikar SD. Uterine tonic activity of U-3107, a herbal preparation in rats. Indian J Pharmacol. 1999;31:200-3.

34. 34 Williamson EM, Okpako DT, Evans FJ. Endocrine Activity: Antifertility and Sex Hormornes. In: Pharmacological Methods in Phytotherapy Research-Selection, Preparation and Pharmacological Evaluation of Plant Material. Vol. 1 Chapter 11New York: John Wiley and Sons. 1996;191-6.

35. Sookvanichsilp N, Soonthornchareonnon N, Boonleang C. Estrogenic activity of the dichloromethane extract from Pueraria mirifica. Fitoterapia. 2008;79/78):509-14.

36. Pathak S, Prakash AO. Effect of hexane extract of Ferula jaeschkeana on the uterus of adult ovariectomized rats. Anc Sci Life. 1992;12(1-2):231-41.

37. Ruentiz PC. Female Sex Hormones, Contraceptives, and Fertility Drugs. In: Abraham DJ, editor. Burger's Medicinal Chemistry and Drug Discovery. Vol. 3 Chapter 13 USA: John Wiley and Sons Inc. 2003;629-60.

38. Visavadiya N, Narasimhacharya RL. Asparagus Root regulates cholesterol metabolism and improves antioxidant status in hypercholesteremic rats. eCAM. 2009;6(2):219-26.

39. Saengsirisuwan V, Pongseeda S, Prasannarong M, Vichaiwong K, Toskulkao C. Modulation of insulin resistance in ovariectomized rats by endurance exercise training and estrogen replacement. Metabolism. 2009;58(1):38-47.

40. Sumino $H$, Ichikawa S, Yoshida A, Murakami M, Kanda T, Mizunuma $H$, et al. Effects of hormone replacement therapy on weight, abdominal fat distribution, and lipid levels in Japanese postmenopausal women. Int $\mathrm{J}$ Obes. 2003;27(9):1044-51.

41. Antunes IB, Andersen ML, Alvarenga TAF Turfix S. Effects of paradoxical sleep deprivation on blood parameters associated with cardiovascular risk in intact and ovariectomized rats compared with male rats. Behav Brain Res. 2007:176(2):187-92.

42. Subbiah MT. Mechanisms of cardioprotection by estrogens. Proc Soc Exp Biol Med. 1998;217(1):23-9.

43. Wade GN, Gray JM, Bartness TJ. Gonadal influences on adiposity. Int J Obes. 1985;9(1):83-92.

44. Laudenslager ML, Wilkinson CW, Carlisle HJ, Hammel HT. Energy balance in ovariectomized rats with and without oestrogen replacement. Am J Physiol.
1980;238(5):R400-R5.

45. Zaid SS, Sulaiman SA, Sirajudeen KNM, Othman NH. The effect of tualang honey on female reproductive organs, tibia bone and hormonal profile in ovariectomized rats-animal model for menopause. BMC Complement Altern. 2010;10(1):82

46. Agacayak E, Basaranoglu S, Tunc SY, Icen MS, Findik FM, Kaplan I, et al. Oxidant/antioxidant status, paraoxonase activity, and lipid profile in plasma of ovariectomized rats under the influence of estrogen, estrogen combined with progesterone, and genistein. Drug Des Devel Ther. 2015;9:2975-82.

47. Beden S. Effect of postmenopausal hormone treatment on serum lipid profile and coagulation factors. J of Exp Clin Med. 2010;27(3):99-103.

48. Arivazhagan $P$, Thilakavathy $T$, Panneerselvam $C$. Antioxidant lipoate and tissue antioxidants in aged rats. J Nutr Biochem. 2000;11(3):122-7.

49. Searle AJ, Wilson RL. Glutathione peroxidase effect of superoxide, hydroxyl and bromine free radicals on enzyme activity. Int J Radiat Biol. 1980;37(2):213-7

50. Hazem H, Kataya H, AlaaEldin A. Red Cabbage (Brassica oleracea) ameliorates diabetic nephropathy in rats.eCAM. 2008;5(3):281-7.

51. Malinow MR, McLaughlin P, Stafford C. Prevention of hypercholesterolemia in monkeys (Macaca facicularis) by digitonin. Am J Clin Nutr. 1978;31(5):814-8.

52. Cayen MN. Effect of dietary tomatine on cholesterol metabolism in the rat. J Lipid Res. 1971;12(4):482-90.

53. Sidhu GS, Oakenfull DG. A mechanism for the hypocholesterolaemic activity of saponins. Br J Nutr. 1986;55(3):643-9.

54. Harwood HJ, Chandler CE, Pellarin LD, Bangerter FW, Wilkins RW, Long CA, et al. Pharmacologic consequences of cholesterol absorption inhibition: alteration in cholesterol metabolism and reduction in plasma cholesterol concentration induced by the synthetic saponin ß-tigogenin cellobioside (CP-88818;tiqueside) J Lipid Res. 1993;34(3):377-95.

55. Han LK, Zheng YN, Xu BJ, Okuda H, Kimura Y. Saponins from Platycodi radix ameliorate high diet-induced obesity in mice. J Nutr. 2002;132(8):2241-5.

56. Howell TJ, MacDougall DE, Jones PJH. Phytosterols partially explain differences in cholesterol metabolism caused by corn or olive oil feeding. J Lipid Res. 1998;39(4):892-900.

Cite this article: Ladachart Taepongsorat, Methin Phadungkit. Effects of Asparagus racemosus Root Extracts on Serum Lipid Profiles, Lipid Peroxidation and Superoxide Dismutase in Ovariectomized Rat. Pharmacogn J. 2018;10(5):1036-41. 